\title{
ANALISIS HASIL TEKNIK PENYEMBUNYIAN HAK CIPTA MENGGUNAKAN TRANSFORMASI DCT DAN RSPPMC PADA JEJARING SOSIAL
}

\author{
Dwi Ely Kurniawan', Nanda Rachmat Hartadi², Purwono Prasetyawan³ \\ ${ }^{1,2}$ Teknik Informatika, Politeknik Negeri Batam \\ ${ }^{3}$ Teknik Elektro, Universitas Teknokrat Indonesia \\ Email: 1dwialikhs@ @olibatam.ac.id, ${ }^{2}$ nanda.4311401044@ students.polibatam.ac.id, \\ ${ }^{3}$ purwono.prasetyawan@teknokrat.ac.id
}

(Naskah masuk: 08 Maret 2018, diterima untuk diterbitkan: 7 Agustus 2018 )

\begin{abstract}
Abstrak
Perkembangan teknologi internet memberikan kemudahan dalam aktifitas sehari-hari dalam mendapatkan data digital. Seseorang dengan mudah berhak mengklaim data digital sehingga dapar menimbulkan masalah dalam hak cipta suatu data. Salah satu metode yang dikembangkan dalam penelitian ini menggunakan watermark invisible dan digital signature. Teknik penyisipan watermark menggunakan transformasi Discrete Cosinus Transform (DCT) dan Randomly Sequenced Pulse Position Modulated Code (RSPPMC). Hasil dari penelitian diperoleh bahwa dilakukan pengujian pada citra RGB dan grayscale pada masing-masing file JPG dan BMP diperoleh nilai PSNR, dimana untuk file JPG mencapai 54,97 dB dan untuk file BMP mencapai 56,11 dB. Nilai PSNR yang dihasilkan diperoleh bahwa kualitas citra cukup baik, terlihat dari hasil dari histogram analysis citra, sebelum disisipi dan sudah disisipi tidak mengalami perubahan yang mencolok. Pengujian dilakukan dengan upload ke media jejaring sosial, menunjukkan media jejaring Line, Facebook, Flicker, Google Photo, Photo Bucket, TinyPic, dan Imgbb berhasil didecode ulang. Namun pada media jejaring Instagram, Twitter dan Whatsapp gagal didecode ulang, karena jejaring sosial tersebut melakukan kompresi terhadap file citra.
\end{abstract}

Kata kunci: watermark invisible, jejaring sosial, hak cipta, DCT, RSPPMC

\section{ANALYSIS OF COPYRIGHT HIDEVING TECHNIQUES IN SOCIAL MEDIA USING DCT AND RSPPMC TRANSFORM}

\begin{abstract}
The development of Internet technology provides convenience in everyday activities in obtaining digital data. One can easily claim the digital data so that it can cause problems in the copyright of a data. One of the methods developed in this research uses invisible watermark and digital signature. The watermark insertion technique uses Discrete Cosinus Transform (DCT) transformation and Randomly Sequenced Pulse Position Modulated Code (RSPPMC). The result of this research shows that the test on RGB and grayscale image in each JPG and BMP file is obtained by PSNR value, where for JPG file reach 54,97 dB and BMP file reach $56,11 \mathrm{~dB}$. The resulting PSNR values obtained that the image quality is good enough, seen from the results of the histogram analysis image, before inserted and has been inserted did not change significantly. Testing is done by uploading to social networking media, showing network media Line, Facebook, Flicker, Google Photo, Photo Bucket, TinyPic, and Imgbb successfully decoded. But on network media Instagram, Twitter and Whatsapp failed to be decoded again, because the social networking compression of image files.
\end{abstract}

Keywords: watermark invisible, social media, copyright, DCT, RSPPMC

\section{PENDAHULUAN}

Perkembangan teknologi jejaring sosial media saat ini semakin meningkat penggunanya. Data APJI (2017) penetrasi pengguna internet 54,68\% dari 262 juta orang pengguna dengan prilaku pengguna mengakses konten sosial media. Beberapa sosial media yang sering dikunjungi diantaranya; Facebook,
Instagram, Youtube, Google Plus, Twitter, Linkedin, Whatsapp, Telegram dll. Zarella (2010) menjelaskan media sosial adalah media dimana penggunanya dapat dengan mudah berbagi file dan menciptakan pesan, termasuk blog, jejaring sosial, wiki/ensiklopedia online, forum-forum maya. Kemudahan penggunaan media sosial dapat 
dimanfaatkan untuk mendapatkan suatu informasi yang tersedia. Informasi yang diperoleh melalui media sosial merupakan data multimedia yang berupa audio, video dan gambar. Kemudahan dalam mendapatkan suatu informasi pada media sosial, justru membuat penggunaan data multimedia pada media sosial begitu mudah diambil tanpa izin. Salah satu kasus yang pernah terjadi di Indonesia pada bulan Juni 2017 lalu yang diterbitkan oleh media id.techinasia.com, seorang influencer Instagram bernama Danar Tri Atmojo mengungkapkan kekesalan atas tindakan Hipwee yang telah menggugah hasil jepretannya tanpa izin. Hal ini sudah termasuk dalam pelanggaran hak cipta, yang dilakukan oleh pihak yang tidak berhak atas kepemilikan media tersebut dengan melakukan pengambilan tanpa seizin dan memodifikasinya.

Menurut Ditjen HKI, (2013) hak cipta merupakan hak eksklusif bagi pencipta atau penerima hak untuk mengumumkan atau memperbanyak ciptaannya atau memberi izin dengan tidak mengurangi pembatasan-pembatasan menurut peraturan perundang-undangan yang berlaku. Pelanggaran mengenai hak cipta gambar sudah banyak meresahkan masyarakat. Hingga diperlukan suatu keamanan hak cipta data multimedia merupakan hal yang penting, untuk kebutuhan penggunaan data multimedia. Salah satu alternatif untuk penggunaan data multimedia tersebut digunakan watermark.

Beberapa penelitian yang sejenis Utami (2013) melakukan penelitian terkait teknik penyembunyian dengan pemberian kode watermarking metode Randomly Sequenced Pulse Position Modulated Code (RSPPMC) terdiri dari 5 tahapan diperoleh hasil yang baik namun belum ada analisis terhadap kualitas citra. Setiadikarunia (2011) melakukan penelitian watermark citra warna menggunakan Singular Value Decomposition - Discrete Cosine Transform (SVDDCT) berdasarkan Local Peak SNR diperoleh hasil ketahanan yang kuat terhadap kompresi JPEG, cropping dan filtering namun untuk scalling diperkecil dan rotasi dapat merusak kualitas citra. Amrullah (2012) melakukan penelitian analisis dan implementasi watermark menggunakan metode RSPPMC hasil yang diperoleh sangat kuat terhadap serangan Low Pass Filter dengan PNSR baik yakni > $30 \mathrm{~dB}$ namun belum ada analisa terkait citra yang didistribusikan. Penelitian ini merancang teknik penyembunyian hak cipta dengan transformasi DCT dan metode RSPPMC dengan menganalisa hasil distribusi atau pengunggahan ke media jejaring sosial untuk memberikan tanda bukti kepemilikan secara tersembunyi dan mengetahui kualitas citra yang dihasilkan dari proses penyisipan tersebut.

\section{METODOLOGI PENELITIAN}

Metode penelitian dari teknik watermark diilustrasikan pada gambar 1. Sistem yang digunakan untuk proses penyembunyian suatu data gambar kedalam media berupa citra digital. Selain proses penyembunyian data gambar, juga terdapat proses pemisahan data gambar yang disembunyikan ke dalam media citra digital. Setelah dilakukan pengiriman ke berbagai jejaring media sosial.

Pada penelitian citra yang digunakan untuk menampung watermark adalah citra yang berformat .jpg atau .bmp. Pada citra bunga yang ditunjukan pada gambar 1 memiliki ukuran 496 x 328 pixel. Artinya citra bunga.jpg memiliki 496 kolom dan 328 baris pixel. Jumlah keseluruhan pixel yang dimiliki 162.688 pixel dengan perpaduan warna RGB.

Sedangkan watermark yang digunakan untuk disembunyikan di dalam citra adalah watermark yang berformat .jpg atau .bmp. Pada watermark intel.jpg yang ditunjukan pada gambar 1 memiliki ukuran $50 \mathrm{x}$ 50 pixel. Artinya memiliki 50 kolom dan 50 baris pixel. Jumlah keseluruhan pixel yang dimiliki adalah 2500 pixel dengan perpaduan warna RGB.

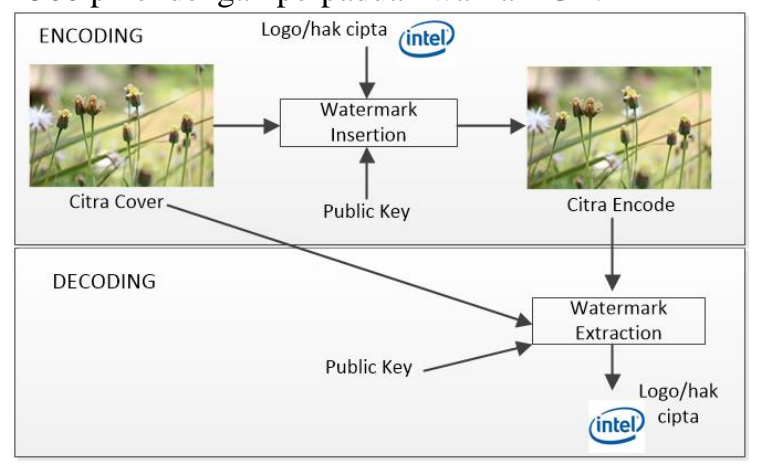

Gambar 1. Ilustrasi Watermark yang Dilakukan

Ilustrasi watermark yang dilakukan diantaranya melakukan proses encoding dan decoding. Encoding adalah proses penyisipan watermark kedalam citra cover. Decoding adalah proses pemisahan (ekstrak) watermark dengan citra encode sehingga watermark dapat dilihat. Citra cover adalah citra yang digunakan untuk media yang akan dilindungi kepemilikanya dengan pemberian label hak cipta yang berupa watermark. Citra encode adalah citra hasil dari proses encoding yang di dalamnya sudah terdapat watermark yang sembunyikan. Watermark adalah citra yang digunakan untuk menyisipkan ke dalam citra cover. Watermark tersebut berformat .JPG atau .BMP memiliki ukuran pixel 50 x 50. Key adalah kunci rahasia yang akan digunakan dalam penyisipan label hak cipta dan digunakan pada saat decoding citra.

Sebelum citra cover dimasukan maka dicek terlebih dahulu, apakah citra cover memiliki mode warna RGB dan apakah pixel citra cover sudah memenuhi standar ukuran yang cukup untuk menampung watermark. Citra cover akan dilakukan perhitungan nilai RGB setiap pixelnya. Kemudian citra watermark akan diproses dengan mengkonversikan menjadi bentuk biner. Password key akan dikonversikan ke biner lalu citra cover akan dihitung nilai koefisien DCT agar proses penyisiapan watermark dapat dilakukan. Jika proses penyisipan 
citra watermark telah selesai maka dilakukan rekonstruksi dengan melakukan invers DCT.

Selanjutnya penyisipan nilai biner password key dan citra hasil encoding akan ditampilkan. Proses decoding pada citra encode membutuhkan citra cover karena nanti citra cover dengan citra encode akan dihitung nilai koefisien DCT untuk mendapatkan watermark yang tersembunyi di dalam citra encode. Pada decoding membutuhkan password key untuk melakukan verifikasi key. Setelah kedua tahap tersebut dapat dilewati maka watermark yang terdapat pada citra encode dapat ditampilkan.

Tahap encoding merupakan tahapan bagaimana sistem membaca sebuah data digital dan melakukan penyisipan berupa watermark. Proses pada encoding pertama memasukan citra cover sebagai media citra yang akan dilindungi hak kepemilikannya, proses kedua memasukan watermark yang kan disisipkan kedalam citra cover sehingga nanti ketika dilakukan proses decoding watermark akan ditampilkan. Berikut flow chart encoding dapat dilihat pada gambar 2.

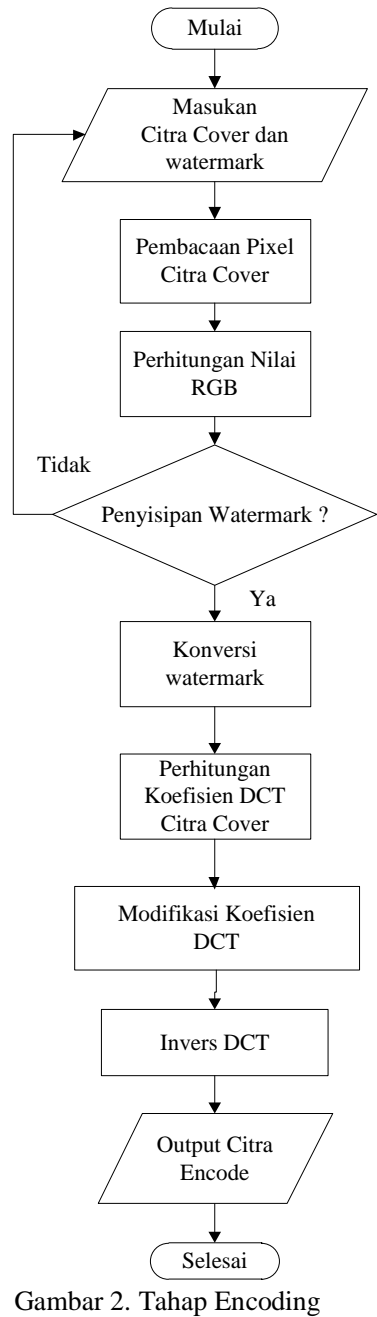

Gambar 2 penyisipan watermark dilakukan dengan berbagai tahapan. Tahapan pertama memasukan citra cover dan watermark, setelah citra cover dan watermark dimasukan sistem akan membaca jumlah pixel pada citra cover dan watermark. Sistem akan melakukan perhitungan nilai warna yang terdapat pada citra cover sehingga nanti dari hasil warna akan didapatkan nilai matrik warna RGB. Proses tahap pertama selesai lanjut dengan proses penyisipan watermark, dalam penyisipan watermark dibutuhkan watermark yang memiliki pixel $50 \times 50$.

Watermark telah berhasil dimasukan sistem akan merubah watermark menjadi grayscale dan watermark akan dikonversikan untuk mendapatkan nilai biner. Nilai biner ini nanti akan dimasukan kedalam citra cover. Tahapan terakhir dengan melakukan perhitungan koefisien DCT dari citra cover yang sudah dimasukan pada tahap awal. Setelah sistem selesai melakukan perhitungan nilai DCT maka langkah terakhir sistem melakukan invers untuk mengembalikan citra yang sudah dilakukan proses DCT agar menjadi dalam bentuk gambar yang sudah terdapat watermark di dalamnya.

Tahapan decoding merupakan tahapan bagaimana sistem melakukan pelepasan watermark yang sudah tertanam pada citra encode. Tahapan pertama citra cover dimasukan untuk dilakukan perhitungan koefisien DCT dan masukan citra encode untuk dilakukan perhitungan koefisien DCT. Berikut flow chart decoding dapat dilihat pada Gambar 3.

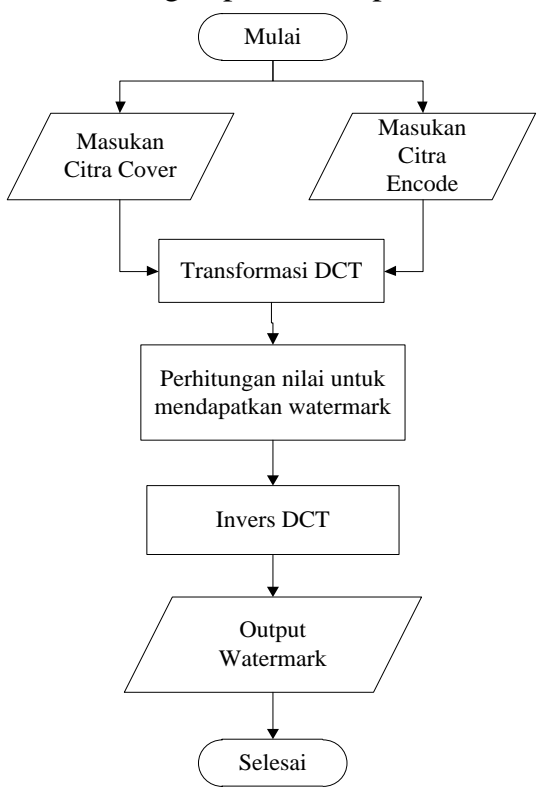

Gambar 3. Tahap Decoding

Gambar 3 merupakan tahapan yang dilakukan untuk melepaskan watermark yang tertanam pada citra encode dengan membutuhkan citra cover dan citra encode. Kedua hal tersebut dibutuhkan dalam proses encoding karena proses encoding tentunya akan membandingkan nilai koefisien DCT yang dihasilkan dari citra cover dan citra encode apakah kedua citra tersebut mengalami perbedaan atau perubahan. Jika dari kedua mengalami perubahan maka watermark akan ditampilkan, namun sebelum watermark ditampilkan ada proses invers DCT terlebih dahulu untuk mengembalikan nilai DCT yang sudah dilakukan perhitungan sebelumnya. 
Setelah proses inverst baru watermark yang tersembunyi di dalam citra encode akan tampil. Tidak semua proses decoding berhasil dengan baik dapat menampilkan watermark yang tersimpan, karena itu semua terkait dengan citra encode atau media yang ingin dilindungi bagaimana kualitas citranya.

\section{HASIL DAN PENGUJIAN}

\subsection{Hasil Implementasi Sistem}

Hasil implementasi berupa aplikasi teknik penyembunyian data digital gambar yang berbasis desktop. Hasil dari watermark akan didistribusikan ke berbagai media jejaring sosial.

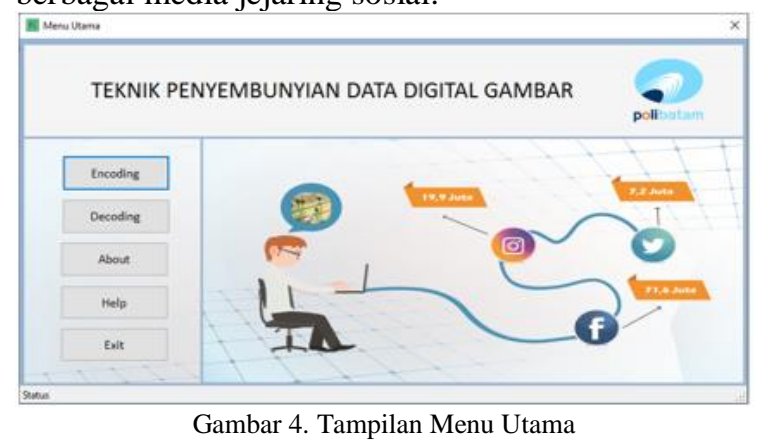

Menu Encoding merupakan bagian dari menu yang memproses citra cover yang akan dilakukan pelabelan berupa watermark di dalam gambar. Proses dari encoding adalah memasukan citra cover terlebih dahulu sebagai citra yang akan dilakukan pelabelan.

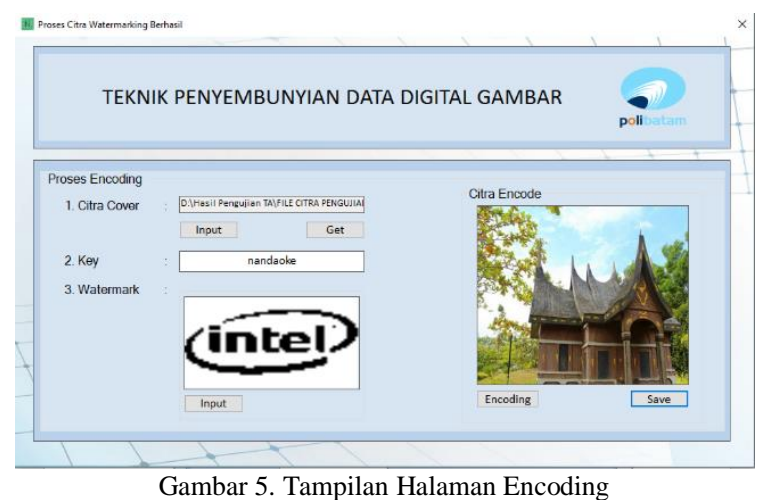

Menu Decoding merupakan bagian dari menu yang memproses pelepasan pelabelan watermark, sehingga watermark yang ditanamkan pada citra encode akan terlihat.

\subsection{Pengujian Sistem}

Pengujian sistem watermark dilakukan untuk mengukur tingkat kualitas citra sebelum dan sesudah proses penyembunyian data digital atau pelabelan. Tahap pengujian dengan melakukan berbagai masukan berupa citra dan watermark yang berbeda format seperti JPG dan BMP. Tahap mengukur tingkat kualitas citra yang dihasilkan dapat menggunakan dengan teori PSNR dan Histogram.
Tahap pengukuran ini dilakukan dengan cara memasukan citra dengan pixel yang sama namun berbeda format sehingga akan dapat mengetahui kualitas dari kedua format yang dihasilkan. Berikut ini adalah proses dari pengujian:

\section{1) Pengujian Encoding}

Pada pengujian encoding terdapat dua pengujian yaitu pengujian pertama berupa format JPG dan BMP yang memiliki mode warna RGB, pengujian kedua berupa format JPG dan BMP yang memiliki warna Grayscale dan RGB. Berikut tabel pengujian encoding.

\begin{tabular}{clcc}
\multicolumn{3}{c}{ Tabel 1. Hasil Pengujian Encoding JPG pada $496 \times 328 \mathrm{px}$} \\
\hline No & Nama File Citra & $\begin{array}{c}\text { Ukuran File } \\
\text { Citra encode }\end{array}$ & $\begin{array}{c}\text { Nilai } \boldsymbol{P S N} \\
\text { (dB) }\end{array}$ \\
\hline 1 & Tutup Botol.jpg & $276 \mathrm{~Kb}$ & 53.65 \\
2 & PhotografiMacro1.jpg & $356 \mathrm{~Kb}$ & 54.97 \\
3 & BungaMerah.jpg & $449 \mathrm{~Kb}$ & 54.02 \\
4 & Pinadrink1.jpg & $457 \mathrm{~Kb}$ & 54.83 \\
5 & Bangunan.jpg & $461 \mathrm{~Kb}$ & 53.88 \\
\hline
\end{tabular}

\begin{tabular}{llll}
\multicolumn{3}{l}{ Tabel 2 . Hasil Pengujian Encoding BMP pada 496 x $328 \mathrm{px}$} \\
\hline No & Nama File Citra & $\begin{array}{l}\text { Ukuran } \\
\text { File Citra } \\
\text { encode }\end{array}$ & $\begin{array}{l}\text { Nilai } \\
\text { PSNR } \\
\text { (dB) }\end{array}$ \\
\hline 1 & Tutup Botol.bmp & $277 \mathrm{~Kb}$ & 53.91 \\
2 & PhotografiMacro1.bmp & $356 \mathrm{~Kb}$ & 55.43 \\
3 & BungaMerah.bmp & $450 \mathrm{~Kb}$ & 54.42 \\
4 & Pinadrink1.bmp & $457 \mathrm{~Kb}$ & 55.33 \\
5 & Bangunan.bmp & $462 \mathrm{~Kb}$ & 54.30 \\
\hline
\end{tabular}

Berdasarkan tabel 1 dan 2 hasil pengujian PSNR yang dilakukan pada citra JPG dan BMP berhasil dengan baik dengan rata-rata nilai PSNR yang cukup baik. Berikut grafik nilai PSNR dari kedua format citra dapat dilihat pada gambar 6 .

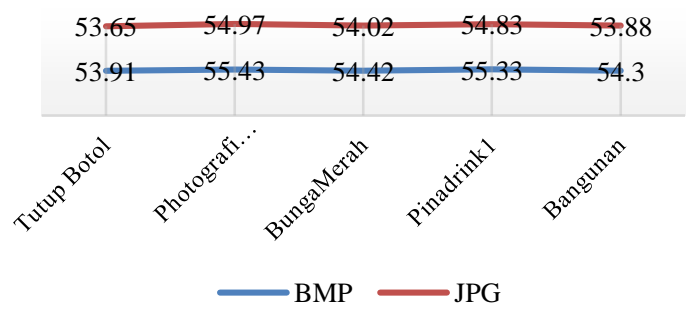

Gambar 6. Grafik Nilai PSNR JPG dan BMP

Dari grafik yang ditunjukan pada gambar 6 dapat diambil kesimpulan bahwa file citra yang berformat JPG maupun BMP tingkat kualitas citra yang dihasilkan sudah cukup baik. Dapat dilihat bahwa masing masing file citra terdapat selisih nilai PSNR dari kedua format tidak begitu signifikan. Rata rata nilai PSNR mencapai $54 \mathrm{~dB}$.

Pengujian kedua dilakukan pada citra RGB dan Grayscale dengan format JPG. Pengujian nilai PSNR dari citra RGB dan Grayscale merupakan cara yang tepat untuk melihat kualitas citra yang dihasilkan dari 
proses encoding yang memiliki citra RGB maupun citra Grayscale.

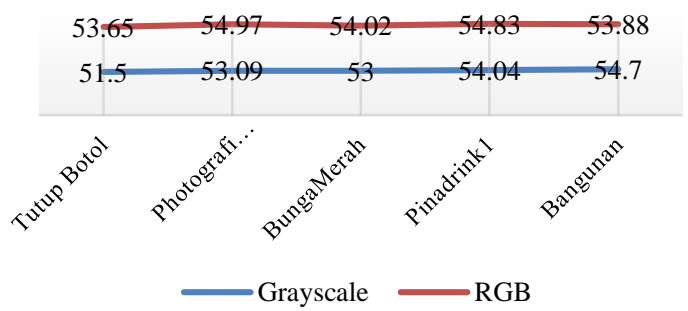

Gambar 7. Grafik Nilai PSNR RGB dan Grayscale format JPG

Berdasarkan hasil pengujian citra format JPG nilai PSNR RGB dan nilai PSNR Grayscale yang dihasilkan cukup baik. Citra RGB dan citra Grayscale tidak memiliki selisih nilai PSNR yang signifikan diantara keduanya bahkan dapat disimpulkan bahwa untuk nilai PSNR dari RGB dan Grayscale yang memiliki nilai rata-rata tertinggi adalah untuk nilai PSNR RGB.

Sedangkan untuk hasil pengujian citra RGB dan citra Grayscale pada format BMP tidak memiliki selisih nilai PSNR yang signifikan diantara keduanya bahkan dapat disimpulkan bahwa untuk nilai PSNR citra BMP dari RGB dan Grayscale yang memiliki nilai rata-rata tertinggi adalah untuk nilai PSNR Grayscale. Berikut grafik nilai PSNR dari citra BMP pada warna RGB dan Grayscale dapat dilihat pada gambar 8 .

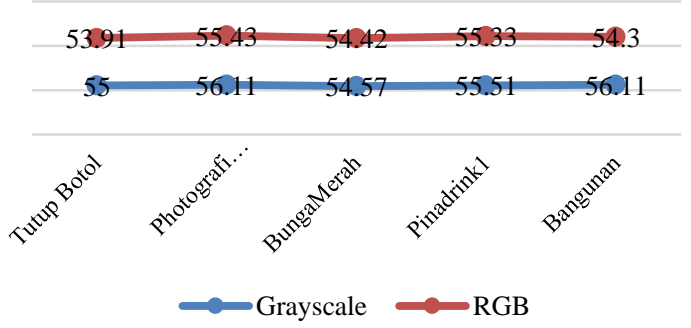

Gambar 8. Grafik Nilai PSNR RGB dan Grayscale format BMP

Berdasarkan dari hasil secara keseluruhan pengujian encoding baik untuk citra RGB dan grayscale pada file JPG dan BMP tidak memiliki selesih nilai, artinya kualitas gambar tetap terjaga.

2) Pengujian Decoding

Pada pengujian decoding terdapat dua pengujian yaitu pengujian pertama melakukan pelepasan watermark dengan menggunakan Key yang sesuai dengan proses encoding sebelumnya. Berikut hasil dari pada pengujian pertama dapat dilihat pada tabel 3.

Tabel 3. Pengujian Decoding

\begin{tabular}{|c|c|c|c|c|c|}
\hline No & $\begin{array}{c}\text { Nama File } \\
\text { Citra }\end{array}$ & $\begin{array}{c}\text { Pixel } \\
\text { Citra } \\
\text { encode }\end{array}$ & $\begin{array}{l}\text { Pixel } \\
\text { Water } \\
\text { mark }\end{array}$ & Key & Watermark \\
\hline
\end{tabular}

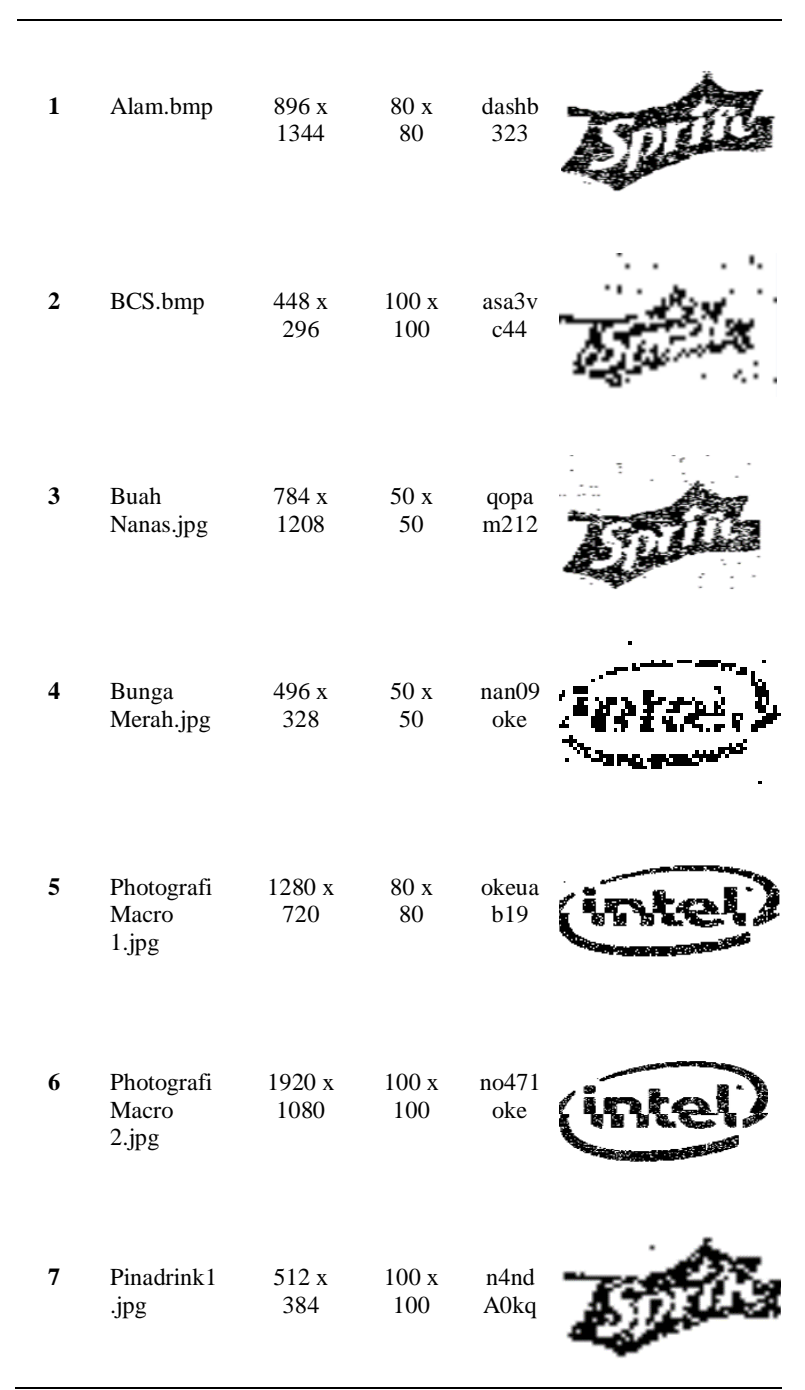

Berdasarkan hasil pengujian yang terdapat pada tabel 3, pengujian decoding untuk melakukan pelepasan watermark yang tertanam pada citra encode sudah sangat baik. Hal ini dapat dilihat pada watermark yang ditampilkan pada tabel 3 watermark dalam keadaan baik dan tidak rusak, namun ada beberapa yang rusak atau watermark tidak jelas. Watermark rusak atau tidak jelas terjadi karena ukuran watermark berukuran kecil yaitu 50 x 50 pixel serta citra cover untuk menampung watermark tersebut berukuran kecil sehingga mengakibatkan watermark rusak jika memang dipaksakan ditanamkan ke dalam citra cover. Berdasarkan data yang ditampilkan pada tabel 3 rata-rata watermark yang ditampilkan tidak rusak adalah file citra yang memiliki format JPG namun watermark yang ditampilkan rusak atau tidak jelas adalah BMP.

Hal ini mungkin dikarenakan pada citra JPG memiliki ukuran pixel yang cukup besar serta watermark yang ditanamkan berukuran kecil dan dapat dikatakan bahwa format file citra JPG lebih bagus digunakan sebagai citra cover untuk ditanamkan watermark. Karena berdasarkan hasil pengujian pada tabel 3 citra bunga merah.jpg berukuran 496 x 328 pixel tersebut didalamnya 
ditanamkan watermark yang memiliki ukuran 50 x 50 pixel, setelah dilakukan proses decoding citra bunga merah.jpg menampilkan watermark yang cukup jelas dibandingkan pada citra rumah adat.bmp yang memiliki ukuran pixel sama yaitu berukuran $496 \mathrm{x}$ 328 pixel dan watermak berukuran 50 x 50 pixel. setelah dilakukan proses decoding citra rumah.bmp menampilkan watermark yang tidak jelas dan rusak.

\section{3) Pengujian Histogram Analisis}

Pengujian histogram analysis ini bertujuan agar dapat mengetahui tingkat perubahan pada citra yang sudah diberikan watermark dan citra sebelum diberikan watermark. Hasil dari pada pengujian histogram analysis tersebut terlihat pada tabel 4 .

Tabel 4. Pengujian Histogram Analysis

$\begin{array}{ll}\text { Nama File Citra : } & \text { Nama File Citra : } \\ \text { Bangunan.jpg } & \text { Bangunan.jpg } \\ \text { Pixel : } 496 \text { x } 328 & \text { Pixel : } 496 \text { x } 328 \\ \text { Citra sebelum disisipi } & \text { Citra sudah disisipi watermark } \\ \text { watermark } & \end{array}$
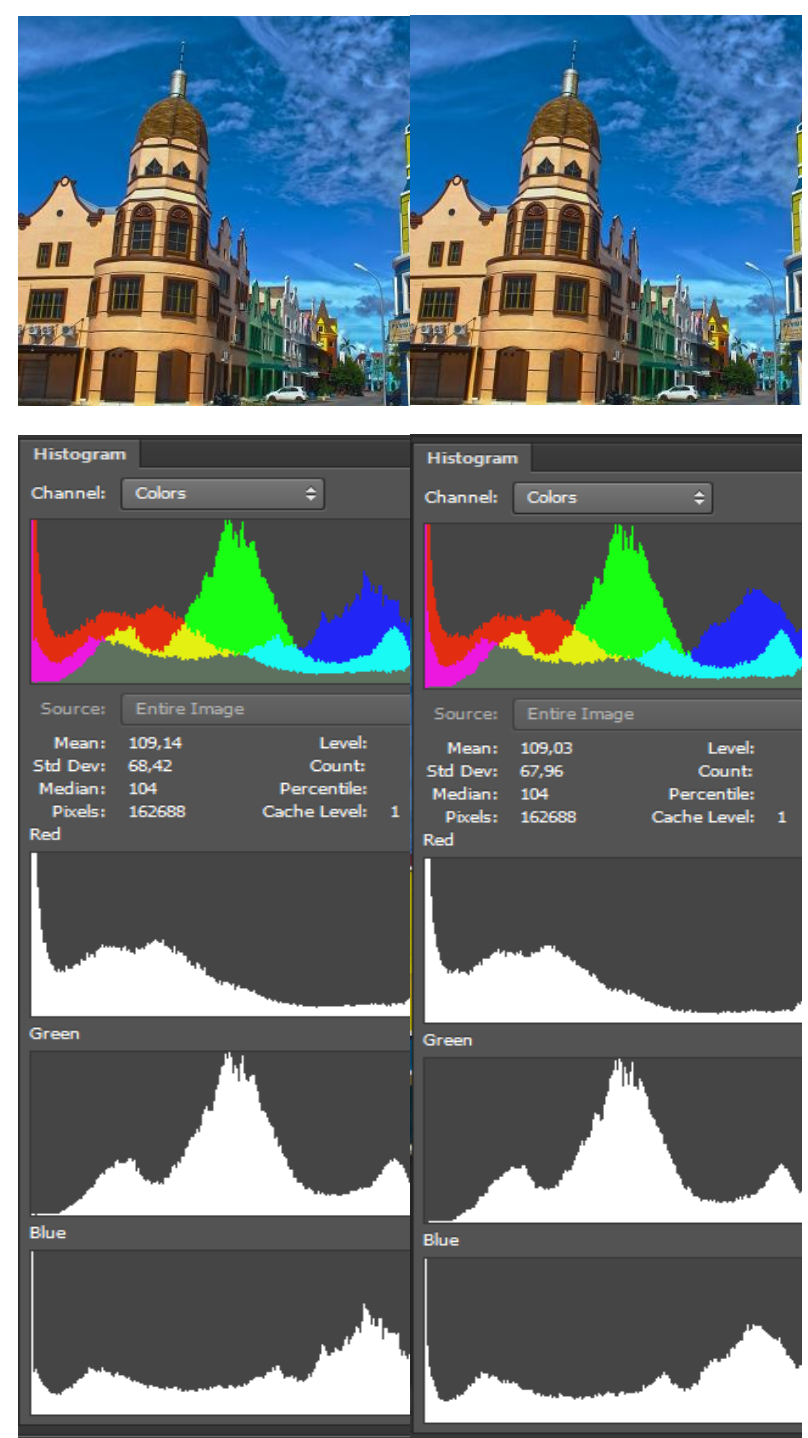

Tabel 5. Pengujian Pengiriman Sosial Media dengan Ukuran Citra Awal $461 \mathrm{~Kb}$

No Media Upload Ukuran $\quad$ Decoding

\begin{tabular}{clcc}
\hline & & $\begin{array}{c}\text { Setelah } \\
\text { Download }\end{array}$ & \\
\hline 1 & Line & $462 \mathrm{~Kb}$ & Berhasil \\
2 & Instagram & $50 \mathrm{~Kb}$ & Gagal \\
3 & Facebook & $337 \mathrm{~Kb}$ & Berhasil \\
4 & Flicker & $463 \mathrm{~Kb}$ & Berhasil \\
5 & Google Photo & $296 \mathrm{~Kb}$ & Berhasil \\
6 & Twitter & $46 \mathrm{~Kb}$ & Gagal \\
7 & Whatsap & $68 \mathrm{~Kb}$ & Gagal \\
8 & PhotoBucket & $462 \mathrm{~Kb}$ & Berhasil \\
9 & TinyPic & $462 \mathrm{~Kb}$ & Berhasil \\
10 & Imgbb & $462 \mathrm{~Kb}$ & Berhasil \\
\hline
\end{tabular}

Berdasarkan dari hasil pengujian pada Tabel 5 yang telah dilakukan maka dapat disimpulkan bahwa file citra yang berhasil dilakukan decoding adalah file citra yang di upload pada media Line, facebook, Flicker, Google Photo, Photo Bucket, TinyPic, dan Imgbb. Masing masing file citra yang di upload berhasil memiliki ukuran yang berbeda-beda.

\section{KESIMPULAN}

Berdasarkan perancangan, implementasi dan hasil pengujian, maka dapat disimpulkan sebagai berikut.

1) Aplikasi memberikan tanda bukti kepemilikan dengan cara melakukan Teknik penyembunyian berupa watermark invisible atau tidak terlihat. Setelah dilakukan pengujian upload ke media sosial dan di analisis hasilnya berhasil pada media Line, facebook, Flicker, Google Photo, Photo Bucket, TinyPic, dan Imgbb.

2) Aplikasi menghasilkan citra watermark invisible, untuk mengetahui kualitas citra watermark invisible dilakukan dengan menganalisis nilai PSNR dan Histogram analysis. Hasil dari menganalisis pada citra JPG dan BMP di peroleh nilai PSNR mencapai 55,43 dB, hasil yang diperoleh untuk citra RGB dan grayscale mencapai 54,97 dB untuk file JPG dan untuk file BMP di peroleh nilai PSNR mencapai 56,11 dB dari ketiga nilai PSNR yang dihasilkan dapat di simpulkan bahwa kualitas citra yang dihasilkan cukup baik. Hasil dari histogram analysis citra yang sebelum disisipi dan sudah disisipi tidak mengalami perubahan yang mencolok, terdapat perubahan grafik sedikit di warna biru.

\section{DAFTAR PUSTAKA}

AMRULLAH, M. S. 2012. Analisis dan Implementasi Image Watermarking Menggunakan Metode Randomly Sequence Pulse Position Modulated Code (RSPPMC). Karya Ilmiah - Skripsi (S1). Universitas Telkom

APJII. 2017, Penetrasi \& Prilaku Penggunaan Internet Indonesia, Diperoleh 24 Juli 2017, dari https://apjii.or.id/survei2017/

KURNIAWAN, D.E. and NARUPI, N., 2016. Teknik Penyembunyian Data Menggunakan Kombinasi Kriptografi Rijndael dan 
Steganografi Least Significant Bit (LSB). Jurnal Teknik Informatika dan Sistem Informasi, 2(3).

KURNIAWAN, D. E. (2013). Identifikasi Citra Wajah Menggunakan Gabor-based Kernel Principal Component Analysis. ABEC. Batam.

MUNIR, R. 2004. Pengolahan Citra digital dengan Pendekatan Algoritmik. Bandung: Informatika

MELINA, S. Hak Cipta Foto, Pelajaran Penting bagi para Pemasar Digital, https://id.techinasia.com/talk/hak-ciptafoto-bagi-pemasar-digital, diakses pada tanggal 20 Juli 2017.

PUTRA, D. 2010. Pengolahan Citra Citra digital. Yogyakarta. Penerbit: ANDI.

UTAMI, E. 2013. Aplikasi Watermarking Sebagai Teknik Penyembunyian Label Hak Cipta Pada Citra Digital Dengan Metode Randomly Sequenced Pulse Position Modulated Code. Fakultas Ilmu Komputer \& Teknologi Informasi Universitas Sumatera Utara, Medan.

RAHMAN, M. 2013. A DWT, DCT and SVD Based Watermarking Technique To Protect The Image Piracy. Department of Computer Science and Engineering, Chittagong University of Engineering and Technology, Bangladesh.

SETIADIKARUNIA, D. and MICHAEL, F., 2012. Watermarking pada Citra Warna Menggunakan Teknik SVD-DCT Berdasarkan Local Peak SNR. Electrical Engineering Journal, 1(2).

SIPAYUNG, W. 2014. Perancangan Citra Watermaking Pada Citra digital Menggunakan Metode Discrete Cosine Transform (DCT). STMIK Budi Darma, Medan.

SUTOYO. T. 2009. Teori Pengolahan Citra digital. Yogyakarta: Penerbit ANDI.

SUBRATA, Rudi. 2014. Perancangan Aplikasi Watermaking Menerapkan Metode Patcwork. STMIK Budi Darma, Medan.

ZARELLA, D. 2010. The Social Media Marketing Book. PT Serambi Ilmu Semesta Anggota IKAPI, Jakarta.

ZEBUA, T. dan NDRURU, E. 2017. Pengamanan Citra Digital Berdasarkan Modifikasi Algoritma RC4. Jurnal Teknologi Informasi dan Ilmu Komputer; Vol 4, No 4 (2017) 
Halaman ini sengaja dikosongkan 